Bangladesh J. Bot. 49(3): 663-670, 2020 (September)

\title{
EFFECTS OF POTASSIUM ON PANICLE STRUCTURE AND SPIKELET MORPHOLOGY OF A DOUBLE GRAINED RICE CULTIVAR
}

\author{
AKM Golam Sarwar*, Al-Muzahid Mridul, Sontosh Chandra Chanda ${ }^{1}$ \\ AND ISRAT J AHAN Shelley \\ Department of Crop Botany, Bangladesh Agricultural University, \\ Mymensingh-2202, Bangladesh
}

Keywords: Multi-floret spikelets, Single-double grain ratio, Yield, Potassium

\begin{abstract}
Influence of $\mathrm{K}$ on panicle structure and spikelet morphology of a double grained rice cultivar was evaluated. Results showed that $\mathrm{K}$ enhanced the plant height, leaf number, yield and yield contributing descriptors in double grained rice cultivar. The ratio of single-double grained spikelets on a panicle varied from $70: 30$ to $59: 41$. The position of spikelets on a panicle viz. primary vs. secondary branch, middle vs. upper or lower portion of panicle, had little effect on single-double grain ratio. However, $\mathrm{K}$ significantly affected the single-double grained spikelet ratio between primary and secondary branches. Multi-grained spikelets showed the potential to increase grain number per panicle thereby increasing rice yield.
\end{abstract}

\section{Introduction}

Rice (Oryza sativa L.), belonging to Poaceae, is one of the most important cereal crops and the staple food for $650 \mathrm{~m}$ hungry, and $80 \%$ of undernourished people of the world (IRRI 2016). The rice spikelets are commonly composed of one pair of rudimentary glumes, one pair of sterile lemmas and one terminal fertile floret. The floret consists of one pair of hulls (lemma and palea) and inner floral organs viz. lodicule(s), stamen(s) and a mono-pistillate ovary with basal placentation; and produces a single grained spikelet. Although clustered spikelets in rice cultivars are relatively common and 254 such varieties were found in 26 countries, mostly in South and South-East Asia (Anon. 2007, Guarino 2012). The multiple pistils (/grains) within a single rice spikelet is a very rare and unique character in rice morphology (Sarwar and Chanda 2018) (Fig. 1). Previously, a double grained rice cultivar, Biram sundari, was reported from Birampur Upazila of Dinajpur district with a yield ca. 2.5 - 3.0 t/ha and suitable for cultivation in both Aman and Boro seasons (Anon. 2012, Mitra et al. 2017). It can be used as a potential genetic resource for further breeding programme to ensure the food security in future (Ren et al. 2018). Although the genetic/molecular basis of multiple florets(/grains) spikelets development in rice has been described since long ago (Parthasarathy 1936, Morinaga and Tajiri 1941, Kasahara 1944, Li et al. 2007, Mitra et al. 2017, Zhang et al. 2017, Ren et al. 2019, Zheng et al. 2019), reports on morphology and/or developmental anatomy are scanty (Nasiruddin 1963, Shimizu and Kuno 1966, Sarwar and Chanda 2018). Moreover, multiple-seeded rice sometime identified as a separate species of Oryza, O. plena (Prain) Chowdhury (Chowdhury 1949). Traditional rice cultivars are generally taller and susceptible to lodging. The present study was, therefore, undertaken to study the panicle structure and spikelet morphology of double grained rice cultivar following $\mathrm{K}$ application which resists lodging by controlling osmosis and turgor pressure, and by the cell wall construction.

*Author for correspondence: <drsarwar@bau.edu.bd>. ${ }^{1}$ Department of Agriculture Extension, Sirajganj, Bangladesh. 


\section{Materials and Methods}

An experiment was conducted at field laboratory of the Department of Crop Botany, Bangladesh Agricultural University during Aman (July - December) season 2017. Seeds of a multiple grained rice cultivar were collected from a farmer of Satkhira district. The experiment was laid out in RCBD with 4 treatments, namely (i) control, (ii) recommended fertilizer dose (RFD) for traditional cultivars (BARC 2012), (iii) 20\% less K than the RFD, and (iv) 20\% additional K than the RFD, in triplicate. The size of plot was $3.0 \mathrm{~m} \times 2.5 \mathrm{~m}$, where block to block and plot to plot distances were $0.75 \mathrm{~m}$ and $0.5 \mathrm{~m}$, respectively. Healthy rice seedlings of 35 days old were transplanted on $31 \mathrm{July}, 2017$ at the spacing of $25 \mathrm{~cm} \times 15 \mathrm{~cm}$. The standard rice cultivation procedure was followed as described by BRRI (2015). The panicle and yield contributing characters were studied after ripening, $80 \%$ grains with characteristics golden colour, of spikelets.

Data recorded for yield and yield contributing characters were compiled and tabulated in proper form for statistical analyses following MSTAT-C computer package programme (Russel 1986). The mean differences among treatment were adjudged with DMRT at $\mathrm{p}<5 \%$ (Gomez and Gomez 1984).
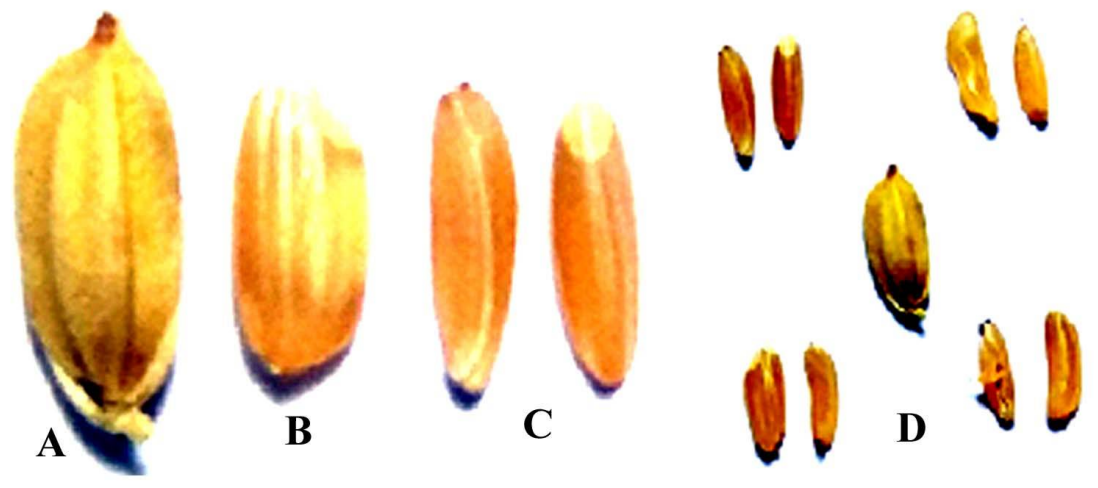

Fig. 1. Double grained rice spikelet. A. A spikelet, B. Single grain and C-D. Double grains

\section{Results and Discussion}

Potassium (K) application significantly enhanced the morphological characters and panicle structure of double grained rice cultivar (Table 1). Twenty per cent additional $\mathrm{K}$ compared to RFD, hereafter $20 \%$ additional K, produced the tallest plant $(162.30 \mathrm{~cm})$ followed by the RFD $(150.50 \mathrm{~cm})$. On the contrary, control showed the shortest plant $(139.80 \mathrm{~cm})$. Similar trends were also observed for number of effective tillers and leaves/hill (Table 1). Nasiruddin (1963) reported that the double grained rice cultivar had normal plant height and panicle length but the individual spikelets differed among themselves by the presence of single, double and triple ovaries. Recently, Sarwar and Chanda (2018) reported that the multiple grained rice cultivar was relatively taller and produced more tillers, longest panicle and bearing more filled spikelets/panicle than hybrid cultivars. Among the treatments, $20 \%$ additional $\mathrm{K}$ resulted better performances on the above traits as compared to other treatments. The increased number of leaves/plant due to $20 \%$ additional $\mathrm{K}$ might increase the photosynthesis rate, which was more helpful for better plant growth and enhancing the yields of double grained rice (Tables 1 and 2). The non-effective tillers and un-filled spikelets also decreased significantly. Banerjee et al. (2018) also reported that the increasing rate of K up to 90 $\mathrm{kg} / \mathrm{ha}$ enhanced the growth of rice by reducing the number of non-effective tillers and un-filled spikelets. 


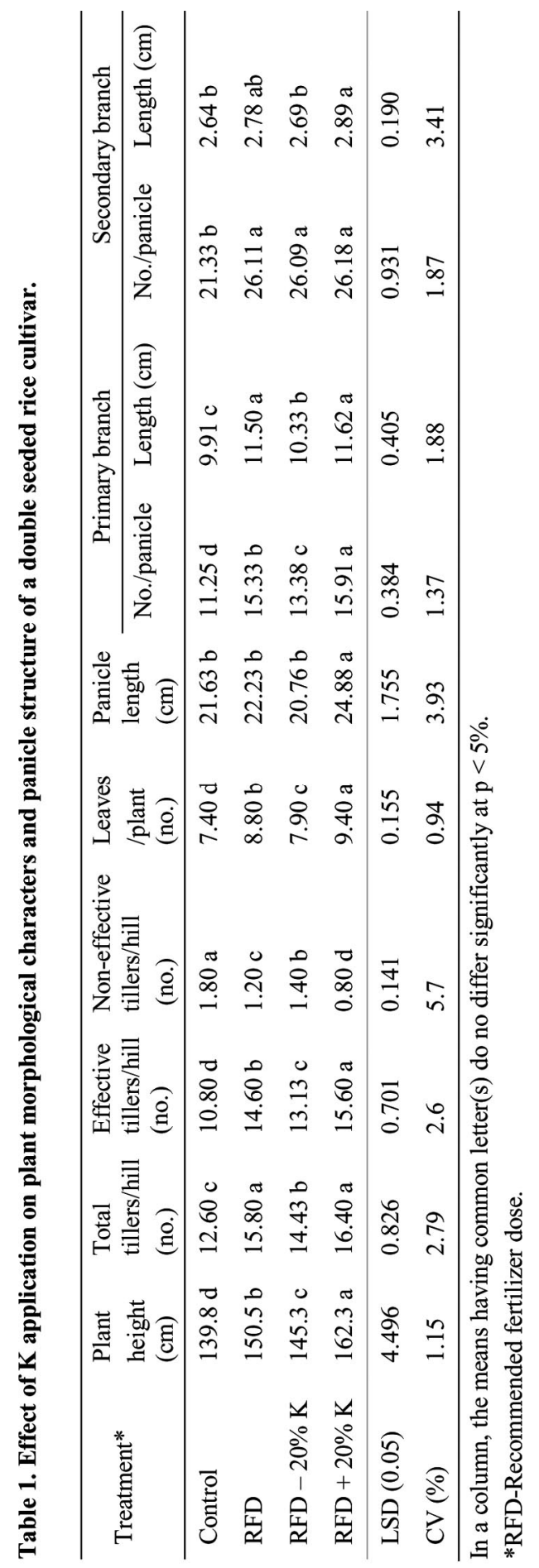


Length of panicle, number and length of primary and secondary branches, and number of filled spikelets are the most imperative characters which evidently influenced the yields of rice crop. The largest panicle $(24.88 \mathrm{~cm})$ was produced in plants receiving $20 \%$ additional $\mathrm{K}$. However, no significant difference among the other treatments was observed (Table 1). Moreover, there was no significant difference in total number of tillers/hill, number of secondary branches/panicle, length of primary and secondary branches between $20 \%$ additional $\mathrm{K}$ and the RFD. Besides, studied double grained local rice cultivar bears more than $40 \%$ double grained spikelet in a panicle which may also increase its production (Fig. 2). The application of K might help to utilize soil $\mathrm{pH}$ and enhanced the amount of macro- and micro-nutrients to the soil which ultimately enhanced the plant growth during the reproductive stage and produced the longest panicle (Islam et al. 2015, Table 1). Number of primary and secondary branches of panicle and their length also varied significantly due to $20 \%$ additional $\mathrm{K}$ and was highly effective for getting better performance. This result indicated that the $20 \%$ additional $\mathrm{K}$ may be adequate for producing more primary and secondary branches of panicle and their length as well. The higher amount of $\mathrm{K}$ enhances the capability of plants to utilize macro- and micro-nutrients which may make the growth condition more favourable for plants to produce more primary and secondary branches of panicle and to elongate their length (Matts 2015).

Length and breadth of spikelets and 1000-grain weight showed significant variations among the different rates of potassium where $20 \%$ additional K showed the largest spikelets (Table 2). These attributes are directly related to grain yield which might be due to the more filled and/or bolder grains that confirm the greater production. The number of filled and un-filled spikelets/panicle of the double grained local rice cultivar varied significantly from 130.6 to 205.40 and 15.00 to 18.77 , respectively among the treatments applied (Table 2). Among the treatments, $20 \%$ additional $\mathrm{K}$ produced more filled spikelets/panicle which was highly effective for reducing the un-filled spikelet and thus produced the lowest number of un-filled spikelets/panicle. Grain and straw yields (5.2 and $6.78 \mathrm{t} / \mathrm{ha}$, respectively) and harvest index (44.35) was the highest due to $20 \%$ additional $\mathrm{K}$ along with the highest spikelet length and width $(6.8$ and $5.9 \mathrm{~mm}$, respectively) and 1000-grain weight (29.97 g) (Table 2). Islam et al. (2015) found that the BRRI dhan59 showed higher response in $80 \mathrm{~kg} \mathrm{~K} / \mathrm{ha}$ to reduce the spikelet sterility and produced bolder grain as well as more filled spikelets and the highest 1000-grain weight. Yields traits such as grain and straw yield, and harvest index of the studied double grained local rice cultivar also varied significantly among the treatments; where $20 \%$ additional $\mathrm{K}$ treatment showed higher and significant performance than that of other treatments (Table 2). The higher grain yield might be due to taller plants with more leaves and effective tillers, longer panicle, more fertile grains and finally heaviest 1000-grain weight recorded under this treatment. The $20 \%$ additional $\mathrm{K}$ treatment also reduced the number of non-effective tillers and un-filled spikelets. Hasanuzzaman et al. (2018) reported that the application of $\mathrm{K}$ increased the spike length by $21.8 \%$, number of spikelets/spike increased up to $23.27 \%$, number of grains/spike increased by $39.24 \%$ and ultimately yield was increased by $30.77 \%$ than without $\mathrm{K}$ application. The yield of double grained rice cultivar (5.2 t/ha) due to $20 \%$ additional $\mathrm{K}$ was comparable to the average yield of modern rice cultivars (Table 2). Moreover, $\mathrm{K}$ imparts resistance to lodging may be another reason for higher yield in this rice cultivar (Matts 2015).

The percentage of double grained spikelets was usually lower than single grained spikelets in a panicle (Fig. 2). The number of single or double grained spikelets in panicle, primary or secondary branches significantly varied among the treatments where $20 \%$ additional $\mathrm{K}$ showed superiority for getting more single or double grains than the RFD (Table 3). The multiple-grained spikelets were hardly identifiable before removal of the husk (Sarwar and Chanda 2018). The higher production percentage of single grained spikelets (70) was found in main panicle and primary branch of panicle 


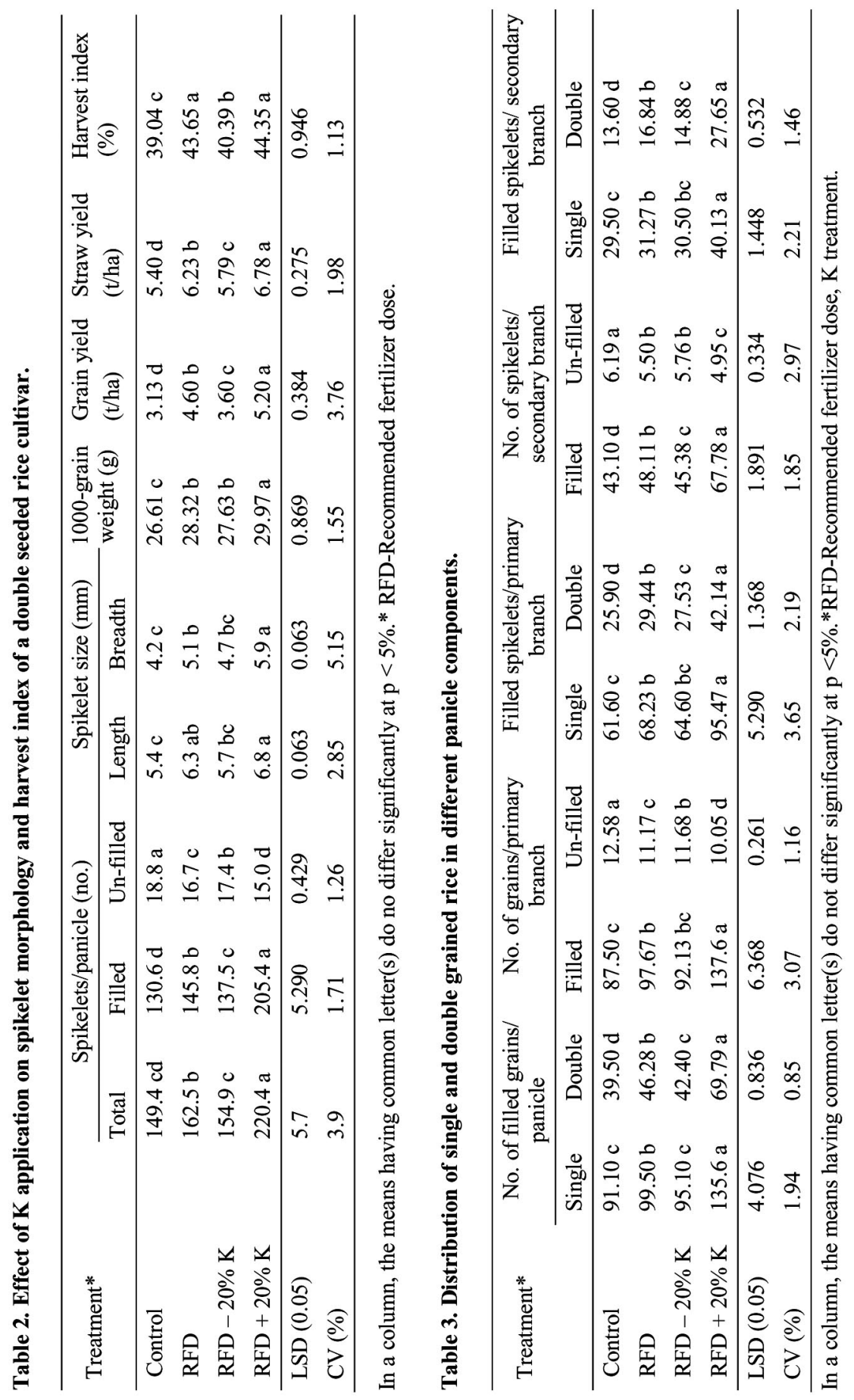


under control, the RFD and $20 \%$ less $\mathrm{K}$ treatments while a relatively higher percentage of double grain (41) was observed in secondary branch of panicle under 20\% additional K treatment (Fig. 2). The value of single-double grained spikelets ratio was lower in all components of panicle viz., whole panicle, primary branch and secondary branches $(70: 30,70: 30$ and $68: 32$, respectively) at control treatment (Fig. 2). On the contrary, the higher values $(66: 34,69: 31$ and $59: 41$, respectively) were observed at $20 \%$ additional $\mathrm{K}$ treatment. The ratio of single-double grained spikelets in a panicle varied from $70: 30$ to $59: 41$ (Fig. 2). Sarwar and Chanda (2018) observed that the $50.28 \%$ spikelets were single grained, $49.30 \%$ double grained and rarely $(0.42 \%)$ triple grained among them while the percentage of double grained spikelets was 50.66 of the total spikelets at the upper portion; 48.69 at the middle and 50.17 at the lower portion. The weight of 1000-(de-hulled) single grained spikelets is comparatively lower than that of double grained spikelets followed by triple grained spikelets also (Sarwar and Chanda 2018). Although the 1000-(de-hulled) double grained spikelets were heavier, the quality especially uniformity in shape and size is a matter of concern (Fig. 1). Mitra et al. (2017) reported the lowest genetic distance between two multi-grain cultivars, Biram sundari and Double rice, which indicates close relations within multi-grain varieties. Guarino (2012) found that the clustered spikelets may be borne directly on the long primary branches of the panicle or on short secondary branches in varying proportions.

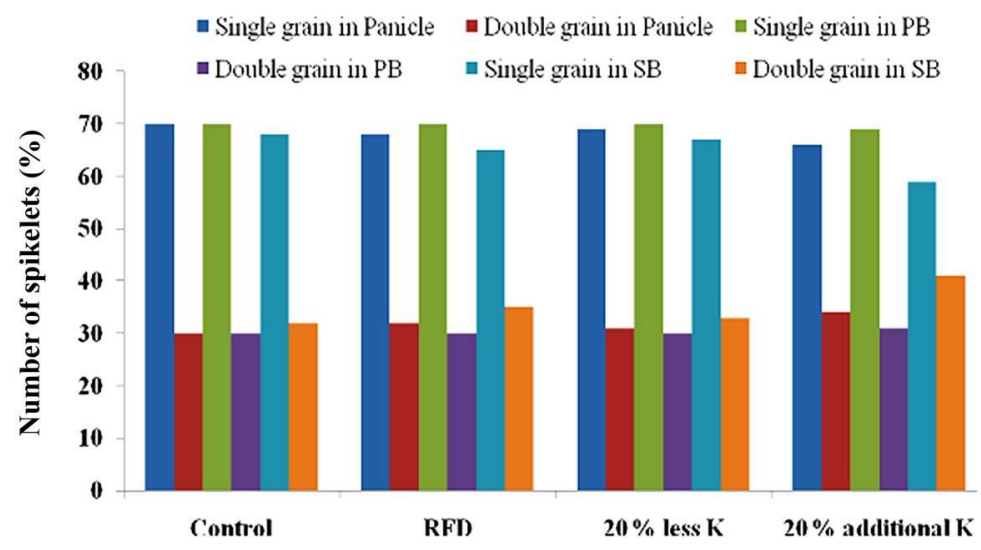

Fig. 2. Proportionate distribution of single and double grained spikelets in different panicle components. RFD - Recommended fertilizer dose, PB - Primary branch and SB - Secondary branch.

The number of double grained spikelets (per panicle) and their distribution pattern on primary and secondary branches of panicle were increased by $\mathrm{K}$ application. An additional K application increased double grained spikelet number per panicle and hence decreased the single to double grained spikelet ratio $(66: 34)$ as compared to control $(70: 30)$, subsequently increased yield. The genetic control of multiple grained rice spikelets has been explained by different authors. For example, the floral organ number mutant, fon $(t)$, controls flower organ identity and produce normal inflorescence structure with additional stamens/pistils in a few flowers (Li et al. 2007). Zhang et al. (2017) reported that the mutation of LF1 induces ectopic expression of OSH1, which results in the initiation of lateral meristems to generate lateral florets in the axil of the sterile lemma. Ren et al. (2019) reported that the fon 4 mutants produced a variable number of multi-floret spikelet, indicating that the mutation of different nucleotides in fon 4 results in variable effects on its ability to control the spikelet determinacy, thereby producing more and less multi-floret spikelet. 
Zheng et al. (2019) also reported that the number of floral organs increased in some spikelets including multi-floret (grain) spikelet, which meant that the spikelet determinacy was lost to some degree in $m f s 3$. Multi-floret spikelets have the potential value in rice breeding to increase grain number per panicle, thereby increasing rice yield (Zhang et al. 2017, Ren et al. 2018, 2019). However, further work is necessary to elucidate the developmental strategies and genetic control of this novel cultivar. As this cultivar is well adapted to local environment, it could be used to boost up the rice production in Bangladesh.

\section{References}

Anonymous 2007. Descriptors for wild and cultivated rice (Oryza spp.). Bioversity International, Italy; International Rice Research Institute, Philippines; WARDA, Africa Rice Center, Benin. p. 37.

Anonymous 2012. Akak dhan, Jhamaj chal. Daily Prothom Alo (A Bangla daily), http://archive.prothomalo.com/detail/date/2012-02-03/news/221684 (in Bengali).

Banerjee H, Ray K, Dutta SK, Majumder K, Satyanarayana T and Timsina J 2018. Optimizing potassium application for hybrid rice (Oryza sativa L.) in coastal saline soils of West Bengal, India. Agronomy 8: 192.

BARC (Bangladesh Agricultural Research Council) 2012. Fertilizer Recommendation Guide 2012. BARC, Farmgate, Dhaka. pp. 251-260.

BRRI (Bangladesh Rice Research Institute) 2015. Adhunik Dhaner Chash. 18 ${ }^{\text {th }}$ ed, BRRI, Gazipur. pp. 1-80. (in Bangla).

Chowdhury NP 1949. A note on the multiple seeded rice of India. Indian Forester 75: 494-499.

Gomez KA and Gomez AA 1984. Statistical Procedure for Agricultural Research. 2nd ed, John Wiley and Sons, New York. p. 680.

Guarino L 2012. Rice morphological diversity. <https://agro.biodiver.se/2012/02/rice-morphologicaldiversity-1-bloggers-0/>.

Hasanuzzaman M, Bhuyan MHMB, Nahar K, Hossain MS, Al-Mahmud J, Hossain MS, Masud AAC, Moumita and Fujita M 2018. Potassium: A vital regulator of plant responses and tolerance to abiotic stresses. Agronomy 8: 31 .

IRRI (International Rice Research Institute) 2016. www.irri.org retrieves on September 13, 2019.

Islam A, Biswas JC, Karim AJMS, Pervin MS and Saleque MA 2015. Effects of potassium fertilization on growth and yield of wetland rice in grey terrace soils of Bangladesh. Research on Crop Ecophysiology 10(2): 64-82.

Kasahara Y 1944. On the characters of a partially two chamber ovary of rice plant and its heredity. Japanese Journal of Crop Science 16(3.4): 54-57. (in Japanese).

Li Y, Xu P, Zhang H, Peng H, Zhang Q, Wang X and Wu X 2007. Characterization and identification of a novel mutant fon $(t)$ on floral organ number and floral organ identity in rice. Journal of Genetics and Genomics 34: 730-737.

Matts I 2015. The role of Potash in plants. Potash News - Potash Development Association, May 2015. <https://www.pda.org.uk/the-role-of-potash-in-plants/>.

Mitra S, Islam T, Sarker RH and Hoque MI 2017. RAPD profile analysis of single and multigrain aman rice (Oryza sativa L.) varieties available in Bangladesh. Plant Tissue Culture and Biotechnology 27: 195-205.

Morinaga T and Jajiri T 1941. The inheritance of polycaryoptic rice, with special reference to the germination structure of the lemma. Japanese Journal of Genetics 17: 57-62. (in Japanese with English résumé).

Nasiruddin M 1963. A study on the developmental anatomy of the panicle and multi-ovary formation of rice. MAg in Crop Botany thesis, Faculty of Agriculture, University of Dhaka. pp. 1-2.

Parthasarathy N 1936. The inheritance of multiple pistils in rice. Proceedings of the Association of Economist and Biologists, Coimbatore 3: 32-41. 
Ren D, Xu Q, Aiu Z, Chi Y, Zhou T, Zeng D, Guo L and Qian Q 2019. FON4 prevents the multi-floret spikelet in rice. Plant Biotechnology Journal 17: 1007-1009.

Ren D, Yu H, Rao Y, Xu Q, Zhou T, Hu J, Zhang Y, Zhang G, Gao Z, Chen G, Guo L, Zeng D and Qian Q 2018. 'Two-floret spikelet' as a novel resource has the potential to increase rice yield. Plant Biotechnology Journal 16: 351-353.

Russel DF 1986. MSTAT-C Package Program. Crop and Soil Science Department, Michigan State University, USA.

Sarwar AKM Golam and Chanda SC 2018. Morphology of a multiple seeded rice (Oryza sativa L.) cultivar of Bangladesh. A poster presented at 5th International Rice Congress, Marina Bay Sands, Singapore, October 14-17.

Shimizu M and Kuno K 1966. Studies on the morphogenic abnormalities in rice spikelets caused by a low temperature. Japanese Journal of Crop Sciences. 35: 91-99. (in Japanese with English summary).

Zhang T, Li Y, Ma L, Sang x, Ling Y, Wang Y, Yu P, Zhuang H, Huang J, Wang N, Zhao F, Zhang C, Yang Z, Fang L and He G 2017. Lateral floret 1 induced the three-florets spikelet in rice. Proceedings of the National Academy of Science of the United States of America (PNAS) 114: 9984-9989.

Zheng H, Zhang J, Zhuang H, Zeng X, Tang J, Wang H, Chen H, Li Y, Ling Y, He G and Li Y 2019. Gene mapping and candidate gene analysis of multi-floret spikelet 3 ( $\mathrm{mfs} 3$ ) in rice (Oryza sativa L.). Journal of Integrative Agriculture 18: 2673-2681.

(Manuscript received on 25 September, 2019; revised on 30 January, 2020) 